\title{
Issues and Challenges in Implementing Research Initiatives at the Faculty of Medicine and Surgery of the University of Santo Tomas
}

\author{
Consuelo B. Gonzalez-Suarez, MD, PhD' \\ Ma Lourdes Domingo-Maglinao, $M D^{1}$ \\ Remedios Dee-Chan, MD, MHPEd' \\ Melinda M. Atienza, MD, MHPEd ${ }^{1}$
}

\section{IN SUMMARY}

1. The Health and Allied Science Cluster composed of the Faculty of Medicine and Surgery, College of Nursing and College of Rehabilitation Sciences had an acceptable accomplishment for research in the academic year 2016-17 in terms of faculty members involved in research, number of publications, and number of research collaborations.

2. The faculty members are actively involved in researches with medical students, residents, and fellows.

3. There are a large number of researches involving the faculty members in collaboration with medical students but these researches await translation into publications.

4. The number of research publications and external grants is within the target set for AY 201819. However, most of these were obtained by less than $20 \%$ of the full-time faculty members. These results imply that there is still a need to improve the research environment with an em-

Consuelo Suarez

bebetsuarez61@gmail.com

I Faculty of Medicine and Surgery, University of Santo Tomas, Manila, Philippines phasis on acquisition of research grants and research publications at the Faculty of Medicine and Surgery (FMS).

5. Strategies are being implemented to improve the research productivity of FMS.

A university is "an institution of higher learning providing facilities for teaching and research and authorized to grant academic degrees."

Merriam and Webster Dictionary [1]

A Center of Excellence is "a department in higher education institution which continuously demonstrates excellent performance in the areas of instruction, research and publication, extension and linkages".

Commission of Higher Education [2]

\section{INTRODUCTION}

From the global perspective, research and development have led to substantial gain in economic productivity. Countries that have invested in research and development are seen to be at the forefront of economic progress and world trade. It has also been observed that researches that are concentrated in universities were shared with the industry, the basic 
knowledge needed for technological innovation [3]. However, there is a wide discrepancy in research productivity in high-income countries ( $\mathrm{HIC}$ ) and low- and middle-income countries (LMIC) like the Philippines. There are numerous factors for this condition, namely: limited access to technology, the distance from the hub of advanced technology (ie, America and Europe), the lack of faculty and personnel skilled in doing researches and the lack of funding to procure advanced research equipment. Universities, especially in the LMICs have a lot of catching up to do in the field of research. Still, it has been observed that postgraduate education and research are not usually the core activities among universities in LMICs. [4]

They are also pressured because of the international university rankings. Rankings are regarded as a way to achieve international recognition, to increase government investment in the university and to recruit international and local faculty and students.[4] The Quacquarelli Symonds or QS university ranking uses clear-cut criteria and well-defined indicators of those criteria. One of the criteria is research, which accounts for $20 \%$ of the possible score of the university. Citations per faculty are the basis of the research score which is computed by the number of citations within five years divided by the number of faculty members in the university. [5] The data is obtained from Scopus. Aside from the $Q S$ global ranking, there is a regional $Q S$ ranking. In the QS global ranking, University of Santo Tomas (UST) is in the \#800 to 100 bracket while in the Asian QS university ranking, the UST is ranked 162 with a four-star rating. In the results of the Asian QS University, UST had a low research output while the student-to-faculty ratio was 17:1.[6]

Aside from international university rankings, universities are accredited by national organizations such as the Philippine Accrediting Association of Schools, Colleges, and Universities (PAASCU).[7] Accreditation is voluntary and it marks an educational institution as having attained a level that meets or exceeds the minimum standard prescribed by the government. The benefits of being accredited include the following, among others: full administrative and financial deregulation, and the authority to revise its curriculum without the Commission of Higher Education's approval. In the accreditation tool, research is one of the eight areas that is being assessed by the accreditation team. Faculty of Medicine and Surgery (FMS) has been accredited lastly in 2017 and was given the level 3 status.
With these findings, the administration of UST has set key result areas (KRA) and key performance indices (KPI) for research and has set targets up to 2020 (Table 1). The research activities of UST are directed by the Office for Research and Innovation, which is headed by the Vice Rector of Research and Innovation. There are seven research centers in the university that are organized according to specialized disciplines. The research centers are as follows:

- Research Center for the Natural and Applied Sciences (RCNAS)

- Research Center for Education and Social Sciences (RCCSEd)

- Research Center for the Culture, Arts, and Humanities (RCCAH)

- Research Center for Health Sciences (RCHS)

- Center for Health Research and Movement Science (CHRMS)

- Center for Religious Studies and Ethics (CRSE)

- Center for Creative Writing and Literary Studies (CCWLS)

The RCHS is the research arm of the Faculty of Medicine and Surgery (UST-FMS). It is one of the two research centers in the university which are directly under the supervision of the college. As such, it is not only responsible for faculty research activities but also coordinates with the different subject areas in the FMS which undertake research activities among its students, such as Clinical Epidemiology, Anatomy, Pharmacology, Preventive Medicine, and Clinical Audiology.

This paper presents an overview of the current status of research, the issues and challenges, and the strategies being undertaken to improve research productivity at the FMS of the UST.

\section{RESULTS}

Data of this report were collected from the different departments of the FMS, Department of Medical Education and Research of the University of Santo Tomas Hospital, Office of Research and Innovation of the University of Santo Tomas.

\section{RESEARCH ACCOMPLISHMENT OF THE UNIVERSITY OF SANTO TOMAS ACADEMIC YEAR (AY) 2016-17}

In the research accomplishment report of the University for AY 2016-17, the FMS was grouped 
with the College of Rehabilitation Sciences and the College of Nursing under the cluster of Health and Allied Sciences (H\&AS). There was a total of 177 faculty members actively involved in research with the Science and Technology cluster (S\&T) having the most number of researchers followed by the Social Sciences and Education cluster (SS\&E); and H\&AS cluster $(29 \%, 28 \%$, and $20 \%$ respectively).

The S\&T cluster generated 145 publications with $138(95 \%)$ of the publications in international peer-reviewed journals; 130 of the publications were in SCOPUS and Web of Science indexed journals. This was followed by the H\&AS cluster which had 104 publications with 88 (85\%) published in SCOPUS and Web of Science indexed journals. SS\&E cluster was ranked third with a total of 65 publications, $44(68 \%)$ of which were in the SCOPUS and Web of Science indexed journals. However, the $\mathrm{H} \& A S$ cluster showed the highest number of publications with foreign co-authors with a total of $48(46 \%)$ followed by the S\&T cluster with 38 (26\%). Research collaboration with foreign institutions was also highest in the H\&AS cluster with $27 \%$, followed by S\&T cluster with $21 \%$. However, there was no publication with students as co-authors in the H\&AS cluster. The S\&T cluster had the most number of publications with students as co-authors with a total of $73(50 \%)$, followed by SS\&E cluster numbering to 18 (28\%).

Overall, the H\&AS cluster had an acceptable accomplishment for AY 2016-17.

\section{RESEARCH ACCOMPLISHMENT OF THE UST- FMS}

Table 1 shows the targets of the UST coming from a different research center and that of the FMS. It also shows the accomplishments for each KPI this recent academic year 2018-19.

As seen in this table, FMS has achieved its target on externally funded research projects. Funds are sourced from the university, pharmaceutical companies and government agencies such as the Philippine Council for Health Research and Development (PCHRD) and the Commission for Higher Education (CHED). However, all of these grants were obtained by only eight faculty members. The number of international publications is 82 , which is not far from the target for 2020 that is 90. Many of these publications are from a collaboration of faculty members from FMS with faculty members from foreign universities. However, only $15.9 \%$ of the faculty members published in national and interna- tional journals for this current school year. The CHED requires $30 \%$ of full-time faculty members to be actively involved in research. There were a greater number of research outputs with student/resident co-authors as compared to the target 2020 . This is because of better reporting of different departments and residents' papers being included in the tally. It is also seen that researches have not been translated into utilization as evidenced by the absence of research output used in policy making and in teaching and learning innovation; and that no equipment has applied for a patent.

Figures 1,2 and 3 present the research performance of FMS from the academic year 2015-16 up to 2018-19. There is an increasing number of publications, both in the national and international scene. The increase in national publications from AY 2017-18 to AY 2018-19 is due to the re-launching of the FMS journal, which has been named as the Journal of Medicine-University of Santo Tomas (JMUST). Its forerunner, the Santo Tomas Journal of Medicine (STJM) (formerly the UST Journal of Medicine) went into hiatus in 2006 (Fig 1).

Funding from international agencies has decreased but those from UST and national agencies have increased. During the last two academic years, the FMS started to provide research loads for faculty members, thus allowing faculty members to do research work on protected time. Teaching has always been the core function of the university, but because of the emphasis on research for national and international accreditation, this strategy has been employed by the administration to improve the research output of the university. There has also been an upsurge in funding from national agencies where research projects are a result of the collaboration of different colleges of the university. The PCHRD funds research projects which are aligned with the priorities of the National Unified Health Research Agenda (NUHRA) for 2017-22.[7] The six research themes are as follows: 1) Responsive health systems, 2) Research to enhance and extend healthy lives, 3) Holistic approaches to health and wellness, 4) Health resiliency, 5) Global competitiveness and innovation in health, and 6) Research in equity and health. With this, it is ensured that research is directed towards the needs of the Filipino society and stimulates national and international partnerships in health research. The expected output of the project includes the 6 Ps of the Department of Science and Technology which are publication, patent, product, people services, places/partnerships, and policies (Fig 2). 
Table 1: Key Result Areas and Key Performance indices for Research and Innovation of the University of Santo Tomas

PROGRAM TREE (Thomasian Reserach Excellence \& Engagements): To become intemationally Acknowledged expert in pioneering and innovative research in the art and humanities, social science, business management and education, health and allied sciences, science and technologyn and the sacred science

\begin{tabular}{|c|c|c|c|c|}
\hline Key Result Area & Key Performance Index & $\begin{array}{l}\text { Accomplishment of } \\
\text { FMS for AY 2018-2019 }\end{array}$ & $\begin{array}{l}\text { Target } 2020 \text { for } \\
\text { the Faculty of } \\
\text { Medicine and } \\
\text { Surgery }\end{array}$ & $\begin{array}{l}\text { Target } 2020 \text { for the } \\
\text { University of Santo } \\
\text { Tomas }\end{array}$ \\
\hline \multirow[t]{5}{*}{$\begin{array}{l}\text { A Globally Compet- } \\
\text { itive Research Force } \\
\text { in Residence }\end{array}$} & $\begin{array}{l}\text { Number of faculty members } \\
\text { involved in research project initi- } \\
\text { ated/sponsored by the research } \\
\text { centers. }\end{array}$ & 5 & 15 & 560 \\
\hline & $\begin{array}{l}\text { Percentage of faculty researchers } \\
\text { with masteral/PhD }\end{array}$ & 74 & $76^{*}$ & $100 \%$ \\
\hline & $\begin{array}{l}\text { Percentage of faculty research- } \\
\text { ers with published works in } \\
\text { peer-reviewed journals/books/ } \\
\text { monographs } \\
\text { a. National } \\
\text { b. International }\end{array}$ & $42(15.9 \%)$ & $65(21 \%)$ & $100 \%$ \\
\hline & $\begin{array}{l}\text { Percentage of faculty researchers } \\
\text { with externally funded projects } \\
\text { a. National } \\
\text { b. International }\end{array}$ & $8(0.4 \%)$ & $15(5 \%)$ & $\begin{array}{l}\text { National: } 68 \% \text { : } \\
\text { International: } 38 \% \text { : }\end{array}$ \\
\hline & $\begin{array}{l}\text { Percentage of faculty researchers } \\
\text { with collaborations }\end{array}$ & 1 & 5 & \\
\hline \multirow[t]{5}{*}{$\begin{array}{l}\text { World Class and } \\
\text { High Impact } \\
\text { Research Projects }\end{array}$} & $\begin{array}{l}\text { Number of externally-funded } \\
\text { research projects } \\
\text { a. National } \\
\text { b. International }\end{array}$ & 17 & 15 & $\begin{array}{l}\text { National: } 100 \\
\text { International: } 60\end{array}$ \\
\hline & $\begin{array}{l}\text { Number of publications in } \\
\text { Thomson Reuters (formerly ISI)/ } \\
\text { SCOPUS indexed journals }\end{array}$ & 82 & 90 & 375 \\
\hline & $\begin{array}{l}\text { Number of publications with } \\
\text { foreign co-author }\end{array}$ & 52 & 60 & \\
\hline & $\begin{array}{l}\text { Number of paper presentations } \\
\text { (oral \& Poster) }\end{array}$ & 107 & 120 & \\
\hline & $\begin{array}{l}\text { Amount of External Grants (in } \\
\text { Million Pesos) }\end{array}$ & 11.5 million & 13 million & \\
\hline $\begin{array}{l}\text { Strong Links } \\
\text { between Teaching } \\
\text { and Research }\end{array}$ & $\begin{array}{l}\text { Number of research outputs with } \\
\text { student/resident co-authors } \\
\text { a. Publication } \\
\text { b. Paper presentations } \\
\text { c. Research-based exhibits }\end{array}$ & $\begin{array}{l}204 \\
\text { (140 students; } \\
64 \text { residents) }\end{array}$ & 100 & $\begin{array}{l}\text { Publication:230 } \\
\text { Paper } \\
\text { Presentation:966 }\end{array}$ \\
\hline \multirow[t]{4}{*}{$\begin{array}{l}\text { Effective Utilization } \\
\text { of Research Output }\end{array}$} & Number of Patents & 0 & 9 & \\
\hline & Number of Utility Model & 0 & 0 & \\
\hline & $\begin{array}{l}\text { Number of Research Output } \\
\text { adopted for Policy \& Decision } \\
\text { making }\end{array}$ & 0 & 1 & \\
\hline & $\begin{array}{l}\text { Number of Research Output on } \\
\text { Teaching \& Learning }\end{array}$ & 0 & 2 & \\
\hline
\end{tabular}

* pertains to number of faculty members with masteral and doctorate degrees

Figure 3 shows the number of faculty with national and international publications as well as a percentage of faculty members who have publication increased from $11.8 \%$ to $15.9 \%$ from AY 2015-16 to AY 2018-19. However, this result still falls short of the $30 \%$ requirement of CHED. 


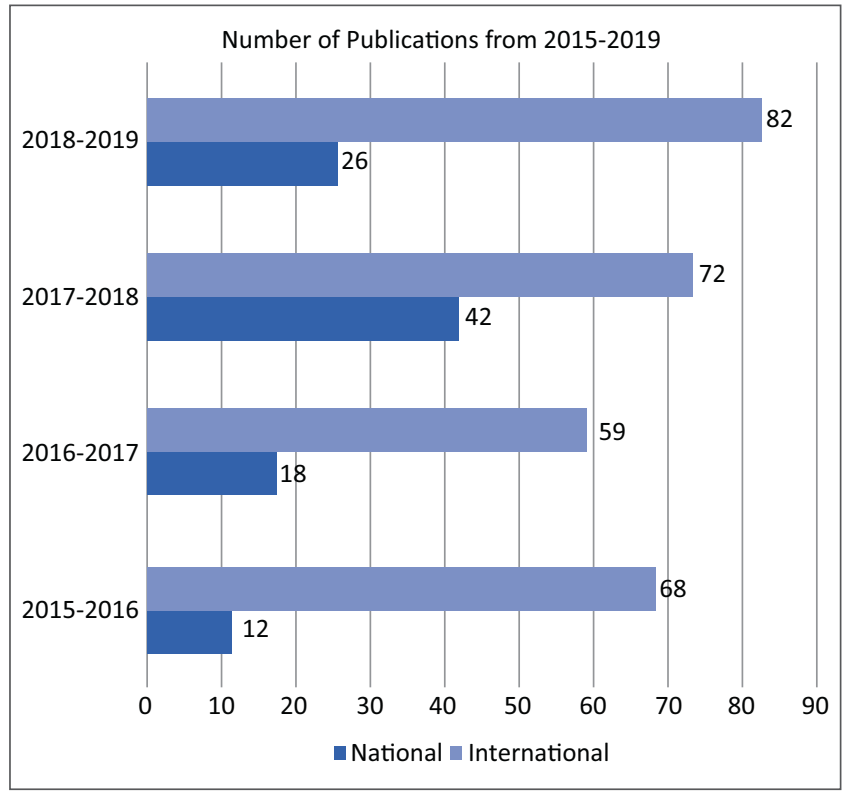

Figure 1. Number of publications from AY 2015-16 to AY 2018-19 of the UST Faculty of Medicine and Surgery (UST-FMS)

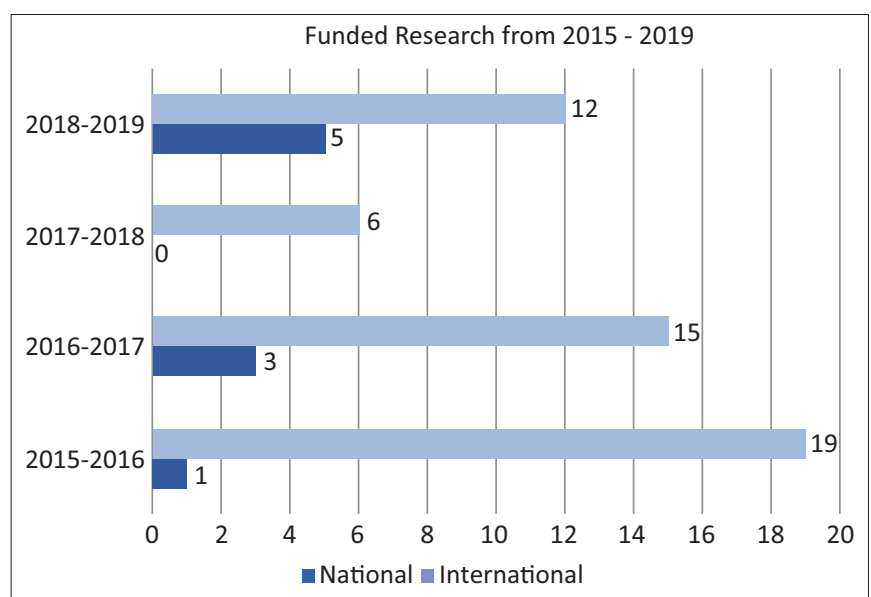

Figure 2. Reported Funded Research from AY 2015-16 to AY 2018-19 for UST-FMS

\section{STRATEGIES IN IMPROVING RESEARCH PRODUCTIVITY AND ENVIRONMENT IN THE UST-FMS}

The UST-FMS is one of the premier medical schools in the Philippines. Its strength is its continuous innovation in medical education and curriculum. It has integrated ultrasound use in its courses for students to enable visualization of bodily structures more cogently. It added courses in the second and third years, namely the Multi-disciplinary Integration 2 (MPPRC) and Multi-disciplinary Integration (IMATY), which provide students with a more holistic understanding of medical conditions, its diagnoses and treatment, even if they still have limited exposure to patient care. The MPPRC is a symptom-based learning activity of horizontally integrated courses for second year

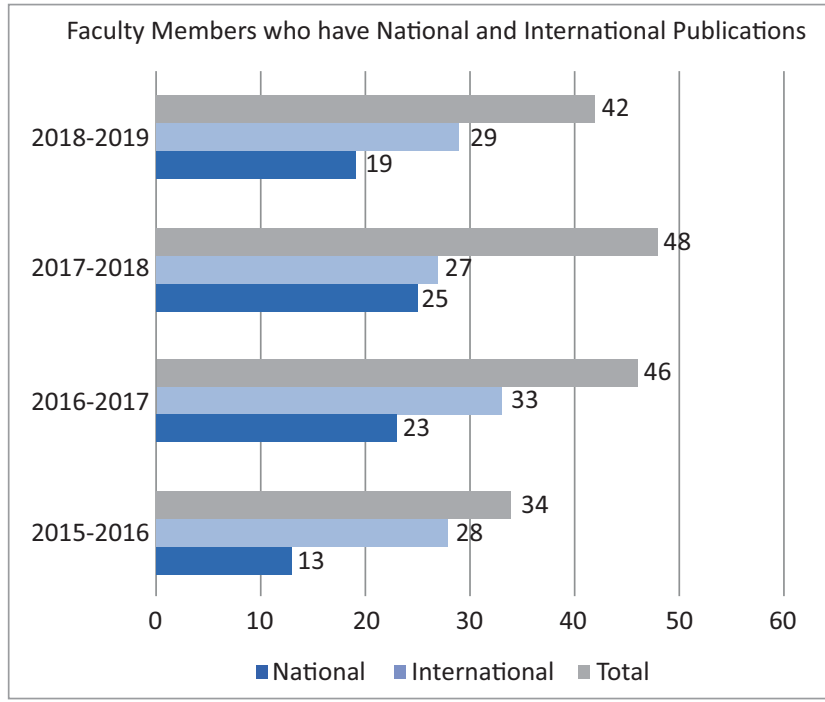

Figure 3. Faculty members of the UST-FMS with national and international publication.

Note: There are faculty members who have national and international publication so that the total for each year may not be the sum of national and international publications

Percentage was obtained by dividing the total number of faculty members over the total of full time faculty for each year which is variable for each year.

medical students while IMATY horizontally integrates courses in the third year and vertically integrates selected first and second year courses. There are also activities by the Medical Curriculum committee which aim to develop, manage, monitor, and evaluate the medical curriculum to ensure that the learning outcomes of different courses in the medical curriculum are constructively aligned with the mission and vision of the FMS, the UST, and the CHED. Educationrelated activities of the FMS include the following: 1) DOTA (Directly Observed Teaching Activities) which involves micro-teaching as a teacher training and faculty development technique for the new faculty members; 2) CC 101 (Curriculum Committee oneon-one) which involves the Curriculum Committee in a regular dialogue with the Chairs of Basic and Clinical departments regarding the Student Feedback Survey results; 3) TAPATAN, which is a regular dialogue with students; and 4) TALAKAYAN are for faculty members' dialogue. Likewise, new courses are being offered in the FMS such as the Master's Program in International Public Health (MS IPH) and the Learning Enhancement Acceleration Program for Medicine (LEAPMED). MS IPH is a transnational program in collaboration with the University of Leeds in the UK, while LEAPMED is an innovative 6-year academic program that leads to a medical degree. There is a wealth of information and data that could be written about these innovations. Sadly, even if 
these innovations are documented, papers are yet to be published in peer-reviewed journals.

Moreover, research is an integral part of medical curriculum where students undertake research projects in the following subjects: Anatomy, Pharmacology, Preventive Medicine and Clinical Epidemiology. There were approximately about 140 researches last AY 2018-19 that were undertaken by medical students with faculty members acting as advisers or co-authors. Aside from the poster presentation of the best papers every academic year which is a part of the requirements of Clinical Epidemiology, student researches with faculty advisers/co-authors are steadily being published.

Cognizant of this situation, the Research Center for Health Science and the Oversight Committee of Research of the FMS have formulated strategies to improve research productivity. Research workshops and lectures are being offered every academic school year to faculty members to enhance their research skills. Topics on good clinical practice, statistics, quantitative and qualitative research designs, writing a research proposal and publication have been offered. A more intensive workshop on writing for publication in medical education will be offered this academic year.

To further develop research knowledge of the faculty members, a PhD in Health Research is being offered by the graduate school of the university. It is a three-year program that will provide foundational course work on research methods in the first year, while the second and third year of study will be devoted to research proposal writing, project implementation, publication, and presentation. Students in this program will be required to have two publications in peer-reviewed local and international journals. It is envisioned that with this program, the graduates will be research savvy and able to acquire advanced competencies in knowledge generation and transmission through publication in their professional areas of practice.

Research collaboration with other disciplines of the university is being established, namely, Engineering, Natural Sciences, Sociology, Education, Allied Health Science, and Psychology. Research collaboration provides a holistic picture of the disease process and management. Medical professionals are so absorbed with the diagnosis and treatment of diseases, but cultural realities may influence the outlook of patients about diseases. Interventions may be more effective if it is related to the lived experiences of the patients. Furthermore, treatment includes pharmacological and non-pharmacological interventions. Non-pharmacological intervention includes patient education, physical activity, and diet which are the expertise of the allied health professionals. Engineering may provide more advanced solutions in the prevention and monitoring of disease processes such as the use of wearable devices and mobile applications. The UST has the distinct advantage of having all specialized professional disciplines housed on one campus. Meeting of research minds is facilitated because of the absence of physical boundaries. With these, more innovative research ideas could be generated with ease.

For student researches, the process of research writing at the Department of Clinical Epidemiology was reviewed and revised so that students will finish their research by their third year. They will submit two versions of their paper, which will be in the thesis and publishable formats, so the research papers could be readily submitted to JMUST or other peer-reviewed journals. Suggestions to streamline researches have been presented to the Departments of Pharmacology and Anatomy. Researches will be faculty-led so that there will be continuity of the researches and the faculty members will be involved from the conceptualization of the research, data gathering and writing of the research for publication.

Support for research is very essential in improving research productivity and the research culture in the Faculty of Medicine and Surgery. Among the support that has been identified are having an ethics committee, physical space for research and having an inhouse statistician. The ethics committee is in the process of completing its standard operating procedures for accreditation with the Philippine Health Research Ethics Board. An eight-floor building will be constructed for FMS and one of the floors will be the home to the Research Center for Health Science. It will house the state of the art research equipment and will provide a space where researchers can stay and focus on the researches that they are presently engaged in. There will also be a conference room where researchers can meet and generate more research ideas.

The FMS is indeed a very fertile ground for research and there are still many avenues for improvement. However, researchers should not only have the "publish and perish" mentality but must also focus their researches on answering the many health issues plaguing Filipino society. 


\section{REFERENCES}

1. University. Merriam Webster Dictionary. 2019.

2. Center of Excellence. Commission on Higher Education; 2019.

3. Guellec D, Van Pottelsberghe De La Potterie B. R\&D and productivity growth: Panel data analysis of 16 OECD Countries. Organisation for Economic Co-operation and Development. STI Working Papers; 2001.

4. UNESCO Institute for Statistics. Higher education in Asia: expanding out, expanding up: the rise of graduate education and university research. UNESCO; 2014.

5. QS World University Ranking. 2019.

6. QS University Ranking: Asia 2019. 2019.

7. Philippine Accrediting Association of Schools, Colleges and Universities. 2019.

8. Philippine National Health Research System; 2019. (c) (i) Open Access This article is licensed under a Creative Commons Attribution 4.0 International License, which permits use, sharing, adaptation, distribution and reproduction in any medium or format, as long as you give appropriate credit to the original author(s) and the source, provide a link to the Creative Commons license, and indicate if changes were made. The images or other third party material in this article are included in the article's Creative Commons license, unless indicated otherwise in a credit line to the material. If material is not included in the article's Creative Commons license and your intended use is not permitted by statutory regulation or exceeds the permitted use, you will need to obtain permission directly from the copyright holder. To view a copy of this license, visit http://creativecommons.org/licenses/ by/4.0/. 